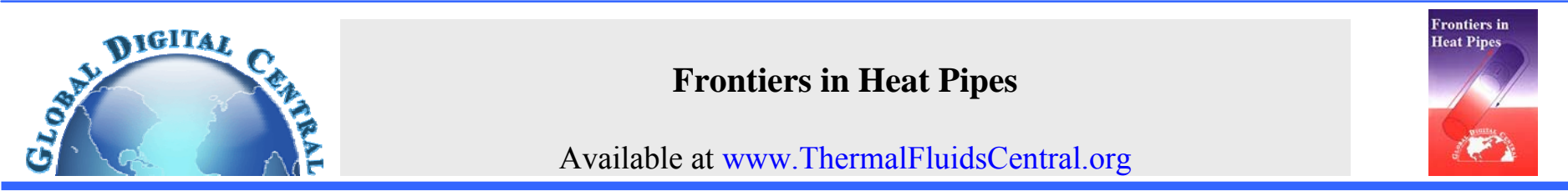

\title{
A REVIEW ON HEAT TRANSFER ENHANCEMENT STUDIES OF HEAT PIPES USING NANOFLUIDS
}

\author{
G. Kumaresan*, S. Venkatachalapathy \\ Department of Mechanical Engineering, National Institute of Technology, Tiruchirappalli, Tamilnadu, India, 620015
}

\begin{abstract}
Heat pipe is a special type of heat exchanger that transfers large amount of heat due to the effect of capillary action and phase change heat transfer principle. Recent development in the heat pipe includes high thermal conductivity fluids like nanofluids, sealed inside to extract the maximum heat. This paper reviews, influence of various factors such as heat pipe tilt angle, charged amount of working fluid, nanoparticles type, size, and mass/volume fraction and its effect on the improvement of thermal efficiency, heat transfer capacity and reduction in thermal resistance. The nanofluid preparation and the analysis of its thermal characteristics also have been reviewed.

Keywords: heat pipe, nanofluid, thermal resistance, capillary pressure, tilt angle
\end{abstract}

\section{INTRODUCTION}

In the emerging world, the field of electronics is one of the fast developing sciences and its contribution to the technology is rapidly growing day by day. During the end of $20^{\text {th }}$ century, most of the electronic devices were larger in size and they had been adopted with fan or micro fin cooling system. These cooling methods occupied considerable volume and did not perform effectively whenever heat dissipation is high and this led to high component temperatures, which affect the performance of electronic devices. Due to the advancement in technology, compact devices were developed to dissipate large amount of heat and one such device is a heat pipe. The heat pipes are suitable devices for the cooling purpose and it was first introduced by Gaugler in 1942. Further developments were made by Groover in 1964 at Los Alamos scientific laboratories (Bejan and Kraus, 2003). The design was further modified and some parameters were changed to improve the performance. These are varying the wick structure (Naphon et al., 2009), base fluids (Senthilkumar et al., 2011), inclination angle (Kiatsiriroat et al., 2000; Naphon et al., 2008) operating pressure (Shafahi et al., 2010; Huminic et al., 2011), charged amount of working fluid (Liu et al., 2011; Mousa et al., 2011), dispersion of nanoparticles in the base fluid (Kiatsiriroat et al.,2000; Mousa et al.,2011), size of particles (Kang et al., 2006; Wang et al.,2010), kind of nanoparticles (Kang et al., 2006; Chen, 2010), mass/volume fraction of nanoparticles (Liu et al., 2011, Teng et al., 2010), heat input (Liu et al., 2011; Do et al., 2010) and geometry (Liu and Zhu., 2011) of heat pipe.

\section{HEAT PIPE AND ITS LIMITATIONS}

A heat pipe contains three different sections; an evaporator at one end, a condenser at other end and an adiabatic section in-between. Figure 1 shows the schematic arrangement of a heat pipe (Kreith and Bohn, 1997). Heat pipe is basically a sealed tube having a wick structure on the inner surface and filled with a fluid at saturated state. Evaporator is the place, where heat is absorbed by the fluid which creates temperature and thus density difference. In the condenser section, heat is rejected to the surrounding medium. The adiabatic section is externally covered with an insulation layer and it is just acting as a flow passage without any heat losses from the working fluid. The addition and removal of heat in the evaporator and condenser sections respectively, induces a pressure difference thus leading to vapor flow from evaporator to condenser. The liquid is retracted into the evaporator due to the capillary pressure in the wick structure and the process repeats.

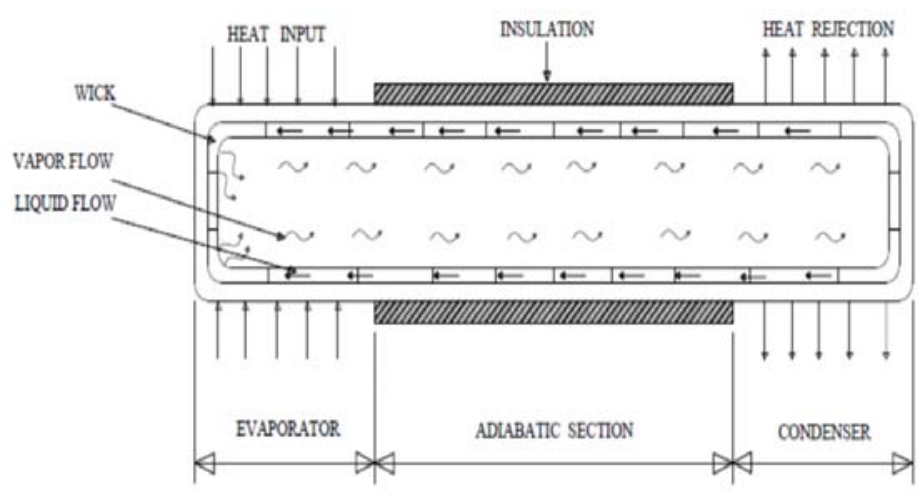

Fig. 1 Heat pipe

The maximum heat transport capacity of a heat pipe is influenced by two limitations; one that leads to heat pipe failure and the other that does not. Limitations that result in heat pipe failure are characterized by insufficient liquid flow to the evaporator for a given heat input, thus resulting in dry out of the evaporator section. The limits categorized under heat pipe failure are capillary limit, boiling limit and entrainment limit. However limitations not resulting in heat pipe failure do require that the heat pipe operate at an increased temperature for an increase in heat input. The three limits are viz. viscous limit, sonic limit and

*Corresponing author E mail : 411111053@nitt.edu 
Condenser limit. Capillary pressure is the pressure difference created between the liquid-vapor interfaces that are essential for the energy transportation in the heat pipe. Sometimes, the driving force is insufficient to move the liquid from condenser to evaporator and evaporator dry out may take place, called capillary limit. An efficient heat pipe always maintains the maximum capillary pressure higher than the total pressure losses inside (Bejan and Kraus, 2003). This is given by the following equations.

$$
\left(\Delta P_{c}\right)_{\max } \geq \Delta P_{\text {tot }}
$$

where, $\Delta P_{\text {tot }}=\Delta P_{v}+\Delta P_{l}+\Delta P_{g}+\Delta P_{p h}$

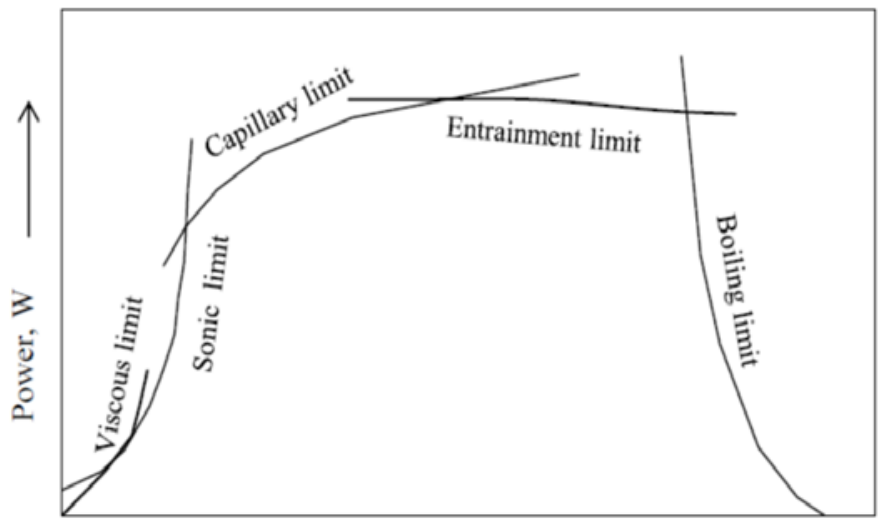

Temperature , ${ }^{\circ} \mathrm{C}$

Fig. 2 Limitations of a heat pipe

When the applied heat flux in the evaporator leads to boiling, vapor bubbles are produced in the evaporator which may partially block the liquid flow coming from the condenser. This causes dry out condition in the evaporator, known as boiling limit. As the vapor passes in the counter flow direction to the liquid, high shear forces are developed. This entrains the liquid and resulting in insufficient liquid flow to the wick structure, known as entrainment limit. Operation of heat pipe at low temperatures creates low vapor pressure which may be insufficient to support the increased vapor flow. This condition is called viscous limit. Choking of heat pipe may occur due to low vapor densities and this is the sonic limit of heat pipe. Ideally, the applied heat flux in the evaporator should be equal to heat rejection from the condenser, which is controlled by convection and radiation to the surroundings and this is called condenser limit.

\section{NANOFLUIDS AND ITS PREPARATION}

In heat transfer applications, conventional fluids like water, oil, refrigerant, etc. are used in heat exchangers, IC engines, refrigerators and air conditioners. Heat transfer capability mainly depends and limited by the thermal conductivity of the working fluid. A method was introduced by Argonne laboratory in 1996 to raise the thermal conductivity of the conventional fluids. In this method nano-sized metallic and non-metallic particles having high thermal conductivity are dispersed in the base fluids (called nanofluids). Some of the commonly used metallic, non-metallic solids and the base fluids and their thermal conductivity values are listed in Table 1 .

Thermal conductivity of a fluid can be improved by adding nanoparticles and thus preparation of nanofluid is important. Nanofluid preparation involves two methods: single step and two step method. The single step method is a process that combining the preparation of nanoparticles with the synthesis of nanofluids. Physical vapor deposition, liquid chemical method and chemical reduction method are some of the methods available to prepare the nanofluid by single step method. The fluid which is prepared by this method gives better stability and reduced agglomeration (collection of tiny particles to form a bulk mass that will settle more rapidly). But the single step method can be used only for low vapor pressure fluids. This method does not have a lengthy preparation process. Liu et al. (2006) prepared $\mathrm{Cu} /$ water nanofluid by chemical reduction method. Eastman et al. (2001) synthesized copper/ethylene glycol nanofluid through physical method. In the two step method, initially nano-scale sized metals, metal oxides, fiber particles and carbon nanotubes (CNT/NCT) are prepared. The dry powder is produced by various processes like chemical vapor condensation, mechanical alloying, etc. Thereafter, it is dispersed in the base fluids. The agglomeration is high in this method, because of its prolonged stages in the preparation. Xie et al. (2002) prepared aluminum oxide with three different base fluids viz. water, ethylene glycol (EG) and pump oil in two step method.

Table 1 Thermal conductivity of solids and liquids (Eastman et al., 1996)

\begin{tabular}{|llc|}
\hline Component & Material & $\begin{array}{c}\text { Thermal } \\
\text { Conductivity, } \\
\text { W/m K }\end{array}$ \\
\hline Metallic solids & Silver & 429 \\
& Copper & 401 \\
Non-metallic solids & Aluminum & 237 \\
& Diamond & 3300 \\
& Carbon nanotubes & 3000 \\
& Silicon & 148 \\
Metallic liquids & Alumina $\left(\mathrm{Al}_{2} \mathrm{O}_{3}\right)$ & 40 \\
Non-metallic liquids & Sodium @ 644K & 72.3 \\
& (values at 300 K) & \\
& Water & 0.613 \\
& Ethylene glycol & 0.253 \\
& Engine oil & 0.145 \\
\hline
\end{tabular}

\subsection{Thermal conductivity of nanofluids}

Thermal conductivity is the primary property that influences the heat transport capacity of nanofluids. Most commonly used nanofluids and the percentage of increase in thermal conductivity values compared with the base fluids are presented in Table 2 .

Table 2 Increase in thermal conductivity of nanofluid

\begin{tabular}{|lll|}
\hline Combinations & $\begin{array}{l}\text { Thermal conductivity } \\
\text { increase }(\%)\end{array}$ & References \\
\hline $\mathrm{Cu} / \mathrm{H}_{2} \mathrm{O}$ & 78 & \\
$\mathrm{Cu} / \mathrm{EG}$ & 40 & Hwang et al.,2006 \\
$\mathrm{Ag} / \mathrm{H}_{2} \mathrm{O}$ & 18 & Choi et al., 2001 \\
$\mathrm{CNT} /$ Poly oil & 160 & Pankaj et al., 2011 \\
$\mathrm{NCT} / \mathrm{s} / \mathrm{EG}$ & 30 & Xuan, and Li, 2000 \\
$\mathrm{TiO}_{2} / \mathrm{H}_{2} \mathrm{O}$ & $30-33$ & Murshed et al., 2005 \\
$\mathrm{Al}_{2} \mathrm{O}_{3} / \mathrm{H}_{2} \mathrm{O}$ & 20 & Xinfang Li et al., \\
& & 2007 \\
& & Xie et al., 2002 \\
\hline
\end{tabular}

Several methods are available to estimate the thermal conductivity of nanofluids. Among them, Transient Hot Wire (THW) method is widely used by many researchers. Xie et al. (2002) in their work used Transient Hot Wire method to measure the thermal conductivity of $\mathrm{Al}_{2} \mathrm{O}_{3} / \mathrm{H}_{2} \mathrm{O}$ nanofluid. Zhang et al. (2007) evaluated the thermal conductivity of $\mathrm{Al}_{2} \mathrm{O}_{3}, \mathrm{TiO}_{2}, \mathrm{CuO}$ and CNT particles with water as base fluid by transient short hot wire technique. Murshed (2012) measured the effective thermal conductivity and thermal diffusivity of $\mathrm{TiO}_{2}$, $\mathrm{Al}_{2} \mathrm{O}_{3}$ and $\mathrm{Al}$ nanoparticles with the varying volume fractions of $1-5 \%$ using a transient double hot wire technique. The effective thermal 
conductivity of a nanofluid can be calculated from the following equation (Li et al., 2009).

$k_{e f f}=\left[\frac{k_{p}+2 k_{b}+\left(k_{p}-k_{b}\right) \phi}{k_{p}+2 k_{b}-\left(k_{p}-k_{b}\right) \phi}\right] k_{b}$

The thermal conductivity of nanofluids is found to increase with particle concentration and aspect ratio. Buongiorno et al. (2009) presented the thermal conductivity of different nanofluids in INPBE (International Nanofluid Property Benchmark Exercise). To validate the results, the experiments were conducted in more than two laboratories. For alumina nanoparticle with $1 \%$ volume fraction, the thermal conductivity ratio (The ratio of nanofluid thermal conductivity to the base fluid thermal conductivity) was $1.039 \pm 0.003$. When the volume fraction increased to $3 \%$, the thermal conductivity ratio increased to $1.121 \pm 0.004$. The reported thermal conductivity ratio was found to be varying from $1.003 \pm 0.008$ to $1.204 \pm 0.010$ for the type of nanofluids and range of volume fractions studied. Higher volume fractions and spherical shape particles gave good thermal conductivity enhancement.

\subsection{Viscosity of nanofluids}

Viscosity and temperature of any liquid is always interrelated with inverse proportionality. For the nanofluids also, the viscosity primarily depends on the temperature and the influence of particle volume fraction is also significant. If the viscosity is measured using capillary viscometer, the radius of capillary tube becomes an important parameter at higher volume fractions. Li et al. (2002) measured the viscosity of $\mathrm{CuO} /$ water nanofluid using capillary viscometer. Ding et al. (2006) investigated and proved that, there is direct proportionality relation between viscosity and particle volume fraction; inverse proportionality relation between viscosity and temperature. Singh et al. (2012) examined the dynamic viscosity and thermal conductivity of CNT-Ethylene glycol nanofluid with concentrations varied between $0.12-0.4 \mathrm{wt} \%$. A rheometer was used to measure the viscosity with differentiating temperature limit of $25-60{ }^{\circ} \mathrm{C}$, the result showed viscosity decreases with increases in temperature and rises with CNT concentrations.

There is no single equation to predict the viscosity of all nanofluids. This is because the different nanoparticles will have different properties and morphology. Various authors have developed equations to predict the viscosity of the nanofluids used in their study. However all formulas have been derived from the basic Einstein's (1906) equation,

$\mu_{n f}=\mu_{b f}(1+2.5 \phi)$

For higher volume fractions, a modified form of this equation was developed by many researchers and Brinkman (1952) proposed the following relation,

$$
\mu_{n f}=\mu_{b f} \frac{1}{(1-\phi)^{2.5}}
$$

For isotropic suspension of spherical and rigid particles, Batchelor (1977) developed a relation to predict the viscosity,

$$
\mu_{n f}=\mu_{b f}[1+2.5 \phi]+6.5 \phi^{2}
$$

Venerus et al. (2009) used an equation to evaluate the viscosity of diluted suspension fluids.

$$
\frac{\mu_{n f}}{\mu_{b f}}=1+[\mu] \phi+O\left(\phi^{2}\right)
$$

where $\mu_{\mathrm{o}} / \mu_{\mathrm{f}}$ is the ratio between zero shear rate viscosity of a diluted suspension and liquid phase viscosity and $[\mu]$ is the intrinsic viscosity, given by $[\mu]=\lim _{\phi \rightarrow 0}\left[\frac{\frac{\mu_{n f}}{\mu_{b f}}-1}{\phi}\right]$

\subsection{Stability of nanofluids}

Nanofluid is a mixture of solid particles and a base fluid. Nanoparticles tend to aggregate with the time due to its high surface activity. The settling down of the particles creates obstruction to the flow velocity and clogging may occur particularly in microchannel flows. Sedimentation method is a simple and widely used one to find the stability of nanofluids. Hwang et al. (2006) measured the stability of various nanofluids such as multi-walled carbon nanotube (MWCNT), fullerene, copper oxide, silicon dioxide and silver nanoparticles in different base fluids like DI water, ethylene glycol, oil, silicon oil and poly- $\alpha$-olefin oil by UV-vis spectrophotometer. The variation of supernatant particle concentration of nanofluid with sediment time was obtained by the measurement of absorption of nanofluids. Li et al. (2007) found that the stability of $\mathrm{Cu} / \mathrm{H}_{2} \mathrm{O}$ nanofluid was affected by $\mathrm{pH}$ value of water and the $\mathrm{Cu}$ particles concentrations.

Usually, the nanofluids taken in a transparent container and monitored for a certain time period and the changes are recorded by a digital camera to observe its stability. The fluids are prepared with the metal nanoparticles like $\mathrm{Cu}, \mathrm{Ag}$ and $\mathrm{Al}$, etc. which has poor stability. In those situations surfactants are mixed with nanofluids and thus the stability is improved. Murshed et al. (2005) used a mixture of Oleic acid and Cetyltrimethylammonium bromide (CTAB) surfactant with $\mathrm{TiO}_{2}$ - DI water nanofluid to improve its stability. Nanoparticle concentrations, viscosity and $\mathrm{pH}$ value of base fluids affect the stability of nanofluids. Peng and $\mathrm{Yu}$ (2007) prepared and conducted the stability test on different nanofluids like $\mathrm{CuO}, \mathrm{Al}_{2} \mathrm{O}_{3}, \mathrm{Cu}$ and $\mathrm{Al}$ dispersed in DI water by two step method. The results indicated that the nanoparticle concentration, viscosity and $\mathrm{pH}$ value of base fluids mainly affects the stability.

\section{THERMAL PERFORMANCE OF HEAT PIPES}

The thermal conductivity and heat transfer coefficient are the primary properties which play a vital role in the performance of heat pipes. The thermal conductivity of a heat pipe is very high, several hundred times compared with the best conducting metals of a same size. Kiatsiriroat et al. (2000) investigated the thermal performance of a thermosyphon with different mixture contents of TEG (Triethylene Glycol), Ethanol and water. They found that, the heat transfer rate varies with the TEG concentration in the mixture, because of the increase in critical heat flux compared with the ethanol-water mixture. The rate of heat transfer in a thermosyphon mainly depends on the TEG concentration present in the mixture and its flooding limit. Liu and Zhu (2011) studied the effect of $\mathrm{CuO}$ nanofluids on the heat transfer enhancement of a heat pipe with $0.5,0.8,1,1.25,1.5$ and 2 wt.\% concentrations. Peak performance was obtained at $1 \%$ mass fraction and showed similar output for both evaporating and condensing heat transfer coefficients. They also found that the heat transfer coefficient was influenced by the operating pressure and best result was obtained at low pressures. The study was conducted with $7.45 \mathrm{kPa}, 12.38 \mathrm{kPa}$ and $19.97 \mathrm{kPa}$ and better performance was obtained at $7.45 \mathrm{kPa}$ pressures. Shafahi et al (2010) conducted a numerical study on the heat pipe performance analysis using $\mathrm{Al}_{2} \mathrm{O}_{3}, \mathrm{CuO}$ and $\mathrm{TiO}_{2}$ nanofluids. The heat pipe reached maximum heat transport capacity at $5 \%, 7 \%$ and $15 \%$ for $\mathrm{Al}_{2} \mathrm{O}_{3}, \mathrm{TiO}_{2}$ and $\mathrm{CuO}$ nanofluids respectively. When the concentrations exceeded critical level, the heat transport capacity was reduced. Hung et al. (2012) investigated the $\mathrm{CuO}$-water nanofluid heat pipe with varying lengths of $0.3 \mathrm{~m}, 0.45 \mathrm{~m}$ and $0.6 \mathrm{~m}$ with a pipe diameter of $9.52 \mathrm{~mm}$. In this study, the charged volume ratio (CVR), heating power and tilt 
angle were varied. The thermal conductivity was found to be increased with heat input. For the given heat input rates of $20-40 \mathrm{~W}$, the maximum performance was attained at $40 \mathrm{~W}$. The charged volume ratio was varied from $20-80 \%$. The maximum thermal conductivity for a 0.3 $\mathrm{m}$ length heat pipe was achieved at a CVR of $20 \%$ with weight fraction, tilt angle, and heat input of $0.5 \mathrm{wt} . \%, 40^{\circ}$, and $40 \mathrm{~W}$ respectively. Compared with DI water heat pipe an increase of $22.7 \%$ in thermal conductivity was obtained. For $0.45 \mathrm{~m}$ length heat pipe, higher thermal conductivity was achieved at $40 \%$ of CVR, $1 \%$ of weight fraction, $40^{\circ}$ tilt angle and $40 \mathrm{~W}$ heating power. The increase in thermal conductivity was around $56.3 \%$ compared with DI water. The heat pipe thermal conductivity is calculated from the equation,

$\mathrm{k}_{\mathrm{HP}}=\frac{\mathrm{Q}}{\mathrm{A} \Delta \mathrm{T}}$

\subsection{Thermal efficiency}

Thermal efficiency of a heat pipe is the ratio between the cooling load in the condenser (heat rejection) to the power supplied (heat input) in the evaporator. Naphon et al. (2008) in their investigation found that the thermal efficiency increased with the tilt angle of the heat pipe and the CVR of the working fluid. Introducing metallic nanoparticles with certain percentage of mass/volume fraction in the base fluids improved the heat pipe efficiency. Inclination angle of $60^{\circ}$ results in maximum efficiency for DI water. When the DI water was replaced by alcohol with the fluid charged volume ratio remaining same at $66 \%$, the inclination angle reduced to $45^{\circ}$ for the maximum efficiency. For nanoparticles volume fraction of $0.1 \%$, the rise in efficiency was $10.6 \%$ compared with that of deionized water. Senthilkumar et al. (2010) in their investigation found that the thermal efficiency decreased when the tilt angle exceeds $30^{\circ}$ for DI water. For copper-water nanofluid and copper nanoparticles dispersed in the aqueous solution of n-Butanol, the deterioration in thermal efficiency was found for the tilt angles exceeding $45^{\circ}$. Noie et al. (2009) studied the thermal performance of a thermosyphon, filled with $\mathrm{Al}_{2} \mathrm{O}_{3}$-water nanofluid with volume fractions of $1 \%, 1.5 \%, 2 \%, 2.5 \%$ and $3 \%$. The results clearly indicated that the efficiency increases with input power and the increase were large at lower input power and moderate at higher input powers. An efficiency gradient of $14.7 \%$ was obtained for the input power $48.4-97.1 \mathrm{~W}$ and much lower percentage gradient of $2.7 \%$ for $146.3-195.2 \mathrm{~W}$ with the volume fraction remaining same as $2 \%$.

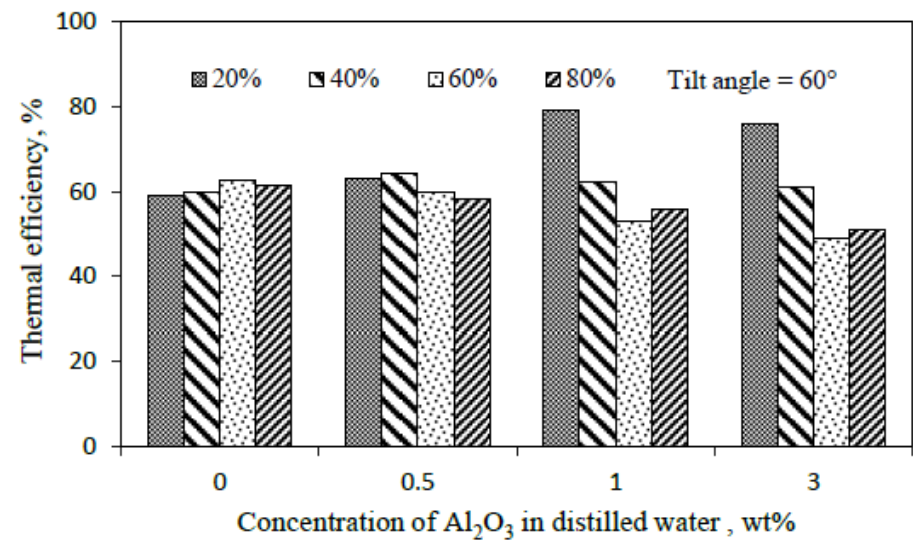

Fig. 3 Thermal efficiency comparison of $\mathrm{Al}_{2} \mathrm{O}_{3}$ nanofluid with different charged volumes (Teng et al., 2010)

Teng et al. (2010) studied the influence of CVR, tilt angle and weight fraction of $\mathrm{Al}_{2} \mathrm{O}_{3}$-water nanofluid on the performance of heat pipe. A tilt angle of $60^{\circ}$ gave maximum efficiency for all the cases. Figure 3 shows the thermal efficiency variation for various concentrations of $\mathrm{Al}_{2} \mathrm{O}_{3}$ nanoparticles and different charged volume ratios. A CVR of $20 \%$ is preferable at higher concentrations, 1 and 3 wt. $\%$.

\subsection{Thermal resistance}

Thermal resistance is a measurement that mainly affects the performance of heat pipes. Heat transport capacity depends on the temperature difference between the evaporator and the condenser ends. The nucleate boiling produces vapor bubbles which may block the liquid flow path and stop the heat transfer process. The addition of high thermal conductivity nanoparticles bombard the vapor bubbles and reduces its size. The thermal resistance of each part of the heat pipe is taken into account for calculating its overall thermal resistance. The mean operating temperature of a heat pipe which is required for estimating the transport limit is obtained from the resistance analogy. The overall thermal resistance (Bejan and Kraus, 2003) comprises of many resistances and the most important are saturated liquid-wick axial resistance $\left(\sim 10^{+4}{ }^{\circ} \mathrm{C} / \mathrm{W}\right)$, pipe wall axial resistance $\left(\sim 10^{+2}{ }^{\circ} \mathrm{C} / \mathrm{W}\right)$ and saturated liquid-wick resistances for the condenser and evaporator ends $\left(\sim 10^{+1}{ }^{\circ} \mathrm{C} / \mathrm{W}\right)$. Thermal resistance is defined as the ratio between the temperature difference in evaporator and condenser to the heat supplied.

$$
R=\frac{T_{e}-T_{c}}{Q}
$$

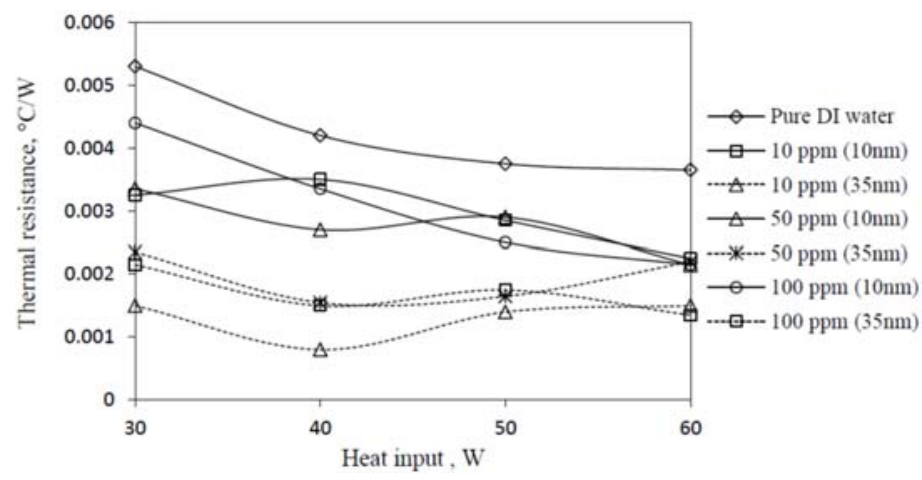

Fig. 4 Thermal resistance comparison of DI water and Ag nanofluids

Figure 4 shows the variation of thermal resistance with heat supplied for Ag nanofluid. The minimum thermal resistance was obtained for $10 \mathrm{ppm}$ concentration and $35 \mathrm{~nm}$ size. Size of the nanoparticles affects the thermal resistance of heat pipe. Kang et al. (2006) in their study found that $10 \mathrm{~nm}$ size Ag nanoparticles with 1 ppm concentration and $50 \mathrm{~W}$ heat input reduced the thermal resistance by $52 \%$ compared with DI water. For the same heat pipe with $35 \mathrm{~nm}$ size particles and $10 \mathrm{ppm}$ concentration, the thermal resistance was reduced by $81 \%$ compared with DI water at $40 \mathrm{~W}$ input. Senthilkumar et al. (2011) used copper nanoparticle in two base fluids viz. DI water and $\mathrm{n}$-Hexanol. The thermal resistance of copper nanofluid with aqueous solution of n-Hexanol was the lowest and does not vary much with heat input. Huminic, G. and Huminic, A., (2011) found that the thermal resistance reduced with increasing tilt angle in two phase closed thermosyphon using iron oxide nanofluid. The study conducted with different inclination angles, $30^{\circ}, 45^{\circ}, 60^{\circ}$, and $90^{\circ}$; iron oxide concentrations of $2.0 \%$ and $5.3 \%$. Lowest thermal resistance was obtained at $90^{\circ}$ inclination angle and $5.3 \%$ volume fraction.

Liu et al. (2011) studied the total heat resistance of a heat pipe. Comparison of pure DI water and $40 \mathrm{~nm}$ size $\mathrm{Cu}$ nanofluid with $1 \%$ volume concentration reduced the resistance. For the working pressure of $7.47 \mathrm{kPa}$ and a heat input less than $85 \mathrm{~W}$, the reduction in total resistance was around $60 \%$ with $\mathrm{Cu}$ nanofluid. When the heat input exceeded $85 \mathrm{~W}$ failure occurred due to dry out condition. Chen (2010) investigated the thermal resistance ratio, which increased with the concentration of the Ag nanoparticles. When the heat input was $40 \mathrm{~W}$ and the concentration being 5,50 and $100 \mathrm{ppm}$, the ratio were 
respectively $0.51,0.69$ and 0.71 . The thermal resistance ratio is given by,

Thermal resistance ratio $=\frac{\mathrm{R}_{\text {water }}-\mathrm{R}_{\text {nanofluid }}}{\mathrm{R}_{\text {water }}}$

Wang et al. (2010) investigated the steady state operation and transient startup process of a $\mathrm{CuO}$ nanofluid heat pipe. Use of nanofluid not only improved the performance during steady operation condition but also reduces the startup time. The reduction in heat resistance was around $50 \%$ whereas the heat transport capacity was increased by $40 \%$ and the study was conducted with concentrations ranging from $0.5-2.0$ wt.\%. Huminic et al. (2011) used iron oxide nanoparticles with the concentrations of $2 \%$ and $5.3 \%$ in a thermosyphon heat pipe. The author reported that the heat transfer increases with increasing nanoparticles concentration and the tilt angle. The improvement in heat transfer was around $39 \%$ and $42 \%$ for the concentrations of $2 \%$ and $5.3 \%$ respectively compared with DI water. Four different sizes of gold nanoparticles, 8, 9.3, 15.6 and $21.3 \mathrm{~nm}$ were used by Tsai et al. (2004). The results were compared with DI water heat pipe and showed a reduction in heat resistance of $23 \%, 20 \%, 37 \%$ and $25 \%$ respectively. Wei et al. (2005) studied the thermal resistance of Ag nanofluid heat pipe with concentrations of 5,10 , and $15 \mathrm{ppm}$. A large reduction in heat resistance was observed, in the range of 30-70\% for 60,80 and $100 \mathrm{~W}$ heat input compared with DI water.

Senthilkumar et al. (2010) studied the effect of tilt angle on thermal resistance using $\mathrm{DI}$ water, $\mathrm{CuO}$-water nanofluid and $\mathrm{CuO}$ dispersed in $\mathrm{n}-$ Butanol. For all the heat inputs and tilts angles, lowest thermal resistance was obtained for n-Butanol with $\mathrm{CuO}$ as shown in Figure 5. Thermal resistance decreased with increasing heat input and a tilt angle of $60^{\circ}$ gave the better performance.

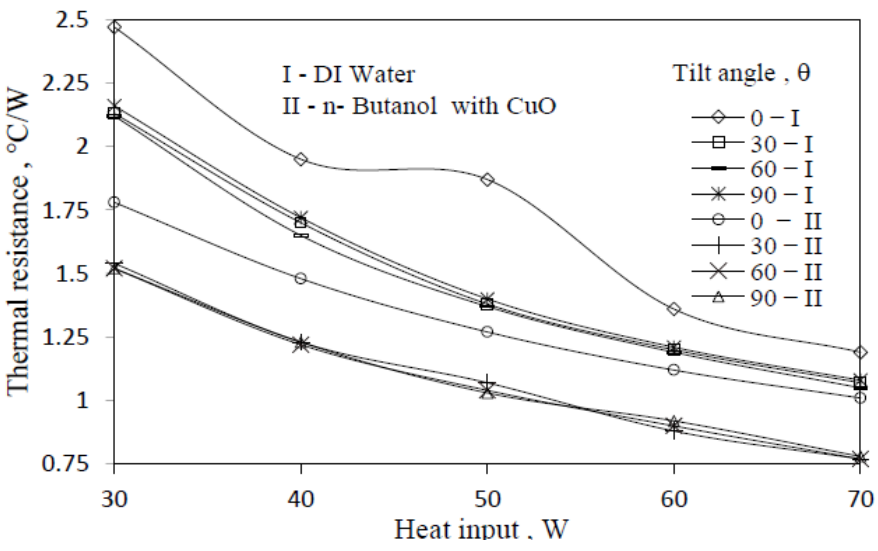

Fig. 5 Effect of tilt angle on DI water and nanofluid heat pipe

\subsection{Temperature distribution}

Wall temperature distribution plays an important role in the performance of heat pipes. The reducing temperature gradient between the evaporator and condenser section results in improved heat pipe performance. Liu et al. (2011) conducted a performance study on micro grooved heat pipes using different kinds of nanoparticles with water as base fluid. Thermal performance was improved with $\mathrm{Cu}$ and $\mathrm{CuO}$ nanoparticles while with $\mathrm{SiO}$ nanoparticles the performance deteriorated. At higher heat inputs, the performance with nanofluid is better whereas failure occurred for deionized water. Kang et al. (2009) used silver nanofluids of 10 and $35 \mathrm{~nm}$, dispersed in deionized water with the concentrations of 1,10 and $100 \mathrm{ppm}$. The heat input for the sintered heat pipe was varied from 30-70 W. For heat input exceeding $50 \mathrm{~W}$, dry out occurred with DI water while an increased performance was evident with silver nanofluid up to $70 \mathrm{~W}$. Another study was conducted by the same authors (2006) using silver nanofluid of same size in grooved circular heat pipe. A drop in wall temperature of around $0.5^{\circ} \mathrm{C}$ was observed with concentration of $1 \mathrm{ppm}$. However the study was extended with different concentrations 10, 50 and $100 \mathrm{ppm}$. The wall temperature distribution decreased with increasing concentrations up to $50 \mathrm{ppm}$ and a rise in temperature was observed beyond $50 \mathrm{ppm}$. Mousa (2011) used the following equation to find the average temperature of evaporator $\left(\bar{T}_{e}\right)$ and condenser $\left(\bar{T}_{c}\right)$ section. The relation is,

$\Delta T=\bar{T}_{e}-\bar{T}_{c}$

where,

$\bar{T}_{e}=\frac{\sum_{i=1}^{i=N_{t_{e}}} T_{e i}}{N_{e}}, \bar{T}_{c}=\frac{\sum_{i=1}^{i=N_{t_{c}}} T_{c i}}{N_{c}}$

where $\mathrm{N}_{\text {te }}$ and $\mathrm{N}_{\mathrm{tc}}$ are the number of thermocouples at the evaporator and condenser ends of the heat pipe.

Do et al. (2010) investigated the temperature distribution of a heat pipe with $\mathrm{Al}_{2} \mathrm{O}_{3}$ nanofluid for different heat inputs and two volume fractions, of $1 \%$ and $3 \%$. The wall temperature was found to increase with heat input for all the cases whereas a reduction was observed with increasing concentrations. A drop in wall temperature of around $26.8^{\circ} \mathrm{C}$ was found at the evaporator end for $3 \%$ volume concentration of nanofluid compared with DI water. Moraveji and Razvarz (2012) used $\mathrm{Al}_{2} \mathrm{O}_{3}$ nanofluid in a sintered circular heat pipe having a bend of $90^{\circ}$ in the adiabatic section. Enhancement in the heat pipe performance was obtained with increasing amount of $\mathrm{Al}_{2} \mathrm{O}_{3}$ dispersion. Lowest temperature was observed in the vicinity of heat pipe bend due to the impact of the vapor flow.

Figure 6 shows the temperature distribution along the length of a heat pipe with inclined grooves. The heat input and the tilt angle were respectively $80 \mathrm{~W}$ and $75^{\circ}$. DI water and $\mathrm{CuO}$ nanofluids were used and lower temperatures were obtained along the length of heat pipe for $\mathrm{CuO}$ nanofluid (Shafahi et al., 2010).

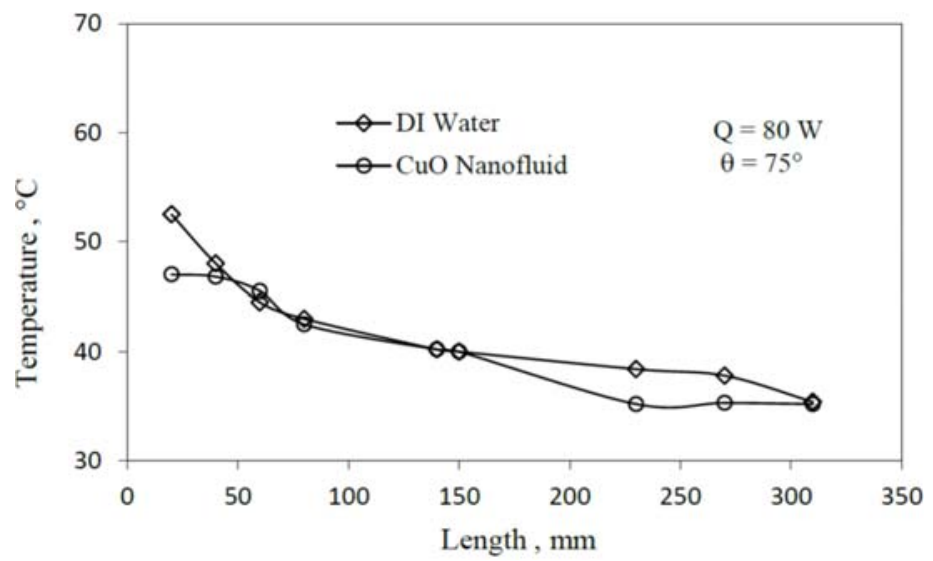

Fig. 6 Temperature distribution comparisons of $\mathrm{CuO}$ nanofluid and DI water

\section{CONCLUSIONS}

The review reports the use of conventional fluids and different nanofluids with varying mass/volume fractions in heat pipes. Nanoparticles like $\mathrm{Ag}, \mathrm{Au}, \mathrm{Cu}, \mathrm{CuO}$ and $\mathrm{Al}_{2} \mathrm{O}_{3}$ were dispersed in various base fluids. Replacing the conventional fluid by nanofluid reduces the dry out problems and enhances the heat transfer capacity. Improvement in thermal efficiency and reduction in thermal resistance is witnessed with increasing mass/volume fraction of nanoparticles in base fluids. Orientation of the heat pipe also affects its thermal performance. The optimum performance is obtained at a tilt angle of around $60^{\circ}$ for wick heat pipes and vertical position for thermosyphon heat pipes. Size of nanoparticles and its concentration has a strong 
influence on the temperature distribution. Effect of heat pipe geometry and its impact on heat transfer characteristics could be explored in future. Uses of hybrid nanofluids in heat pipes have also been deliberated.

\section{NOMENCLATURE}

$\begin{array}{ll}\text { A } & \text { area }\left(\mathrm{m}^{2}\right) \\ \mathrm{I} & \text { current }(\text { Ampere }) \\ \mathrm{k} & \text { thermal conductivity }(\mathrm{W} / \mathrm{mK}) \\ \mathrm{Q} & \text { heat supplied to the heat pipe }(\mathrm{W}) \\ \mathrm{R} & \text { thermal resistance }\left({ }^{\circ} \mathrm{C} / \mathrm{W}\right) \\ \mathrm{T} & \text { temperature }\left({ }^{\circ} \mathrm{C}\right) \\ \mathrm{V} & \text { voltage }(\mathrm{Volts}) \\ \Delta \mathrm{P} & \text { pressure drop }\left(\mathrm{N} / \mathrm{m}^{2}\right) \\ \Delta \mathrm{T} & \text { temperature difference }\left({ }^{\circ} \mathrm{C}\right)\end{array}$

\section{Greek symbols}

$\begin{array}{ll}\theta & \text { tilt angle (degree) } \\ \mu & \text { viscosity }\left(\mathrm{Ns} / \mathrm{m}^{2}\right) \\ \phi & \text { volume fraction }\end{array}$

\section{Subscript}

b base

bf base fluid

c condenser, capillary

e evaporator

HP heat pipe

g body force/gravity

$1 \quad$ liquid

max maximum

nf nanofluid

ph phase transition

$\mathrm{p} \quad$ particle

te thermocouples at evaporator section

tc thermocouples at condenser section

tot total

v vapor

\section{REFERENCES}

Batchelor, G.K., 1977, "The Effect of Brownian Motion on the Bulk Stress in a Suspension of Spherical Particles," J. Fluid Mech., 83 (1) 97-117.

http://dx.doi.org/10.1017/S0022112077001062

Bejan, A., and Kraus, A.D., 2003, Heat Transfer Data Book, John Wiley \& Sons, Inc., 1181-121.

Brinkman, H.C., 1952, "The Viscosity of Concentrated Suspensions and Solution," Journal of Chemical Physics, 20(4) 571-581. http://dx.doi.org/10.1063/1.1700493

Buongiorno, J., Venerus, D.C., Prabhat, N., McKrell, T., Townsend, J., Christianson, R., Tolmachev, Y.V., Keblinski, P., Hu, L-W., Alvarado, J.L., Bang, I.C., Bishnoi, S.W., Bonetti, M., Botz, F., Cecere, A., Chang, Y., Chen, G., Chen, H., Chung, S.J., Chyu, M.K., Das, S.K., Di Paola, R., Ding, Y., Dubois, F., Dzido, G., Eapen, J., Escher, W., Funfschilling, D., Galand, Q., Gao, J., Gharagozloo, P.E., Goodson, K.E., Gutierrez, J.G., Hong, H., Horton, M., Iorio, C.S., Jarzêbski, A.B., Jiang, Y., Jin, L.W., Kabelac, S., Kamath, A., Kedzierski, M.A., Kim, C., Kim, J.H., Kim, S., Kieng, L.G., Leong, K.C., Manna, I., Michel, B., Ni, R., Patel, H.E., Philip, J., Poulikakos, D., Reynaud, C., Savino, R., Singh, P.K., Song, P., Sundararajan, T., Timofeeva, E., Tritcak, T., Turanov, A.N., Van Vaerenbergh, S., Wen, D., Witharana, S., Yang, C.C., Yeh, W.H., Zhao, X.Z, Zhou, S.Q, 2009, "A Benchmark Study on the Thermal Conductivity of Nanofluids," J. Appl. Phys. 106, 094312. http://link.aip.org/link/doi/10.1063/1.3245330
Chen, Y., 2010, "Experimental Study of Silver Nanofluid on Flat Heat Pipe Thermal Performance," Journal of Marine Science and Technology, 18(5), 731-734.

http://jmst.ntou.edu.tw/marine/18-5/731-734.pdf

Choi, S.U.S., Zhang, Z.G., Yu, W., Lockwood, F.E., and Grulke, E.A., 2001, "Anomalous Thermal Conductivity Enhancement in Nanotube Suspensions," Applied Physics Letter, 79(14), 2252-2254.

http://dx.doi.org/10.1063/1.1408272

Collier, J.G., and Thome, J.R., 1996, Convective Boiling and Condensation, $3^{\text {rd }}$ ed., Oxford University Press, Oxford.

Ding, Y., Alias, H., Wen, D., and Williams, R.A., 2006, "Heat Transfer of Aqueous Suspensions of Carbon Nanotubes," International Journal of Heat and Mass Transfer, 49, 240-250.

http://dx.doi.org/10.1016/j.ijheatmasstransfer.2005.07.009

Do, K.H., Ha, H.J., and Jang, S.P., 2010, “Thermal Resistance of Screen Mesh Wick Heat Pipes using the Water-based $\mathrm{Al}_{2} \mathrm{O}_{3}$ Nanofluids," International Journal of Heat and Mass Transfer, 53(2526), 5888-5894.

http://dx.doi.org/10.1016/j.ijheatmasstransfer.2010.07.050

Eastman, J.A, Choi, S.U.S., Li, S., Thomson, L.J., and Lee, S.,1996, "Enhanced Thermal Conductivity through the Development of Nanofluids," Materials Science Division, Energy Technology Division 9700 S. Cass Avenue Argonne National laboratory Argonne, 457(3). http://dx.doi.org/10.1557/PROC-457-3

Eastman, J.A., Choi, S.U.S., Li, S., Yu, W., and Thomson, L.J., 2001, "Anomalously Increased Effective Thermal Conductivities of Ethylene Glycol-Based Nanofluids Containing Copper Nanoparticles," Applied Physics Letter, 78(6), 718-720.

http://dx.doi.org/10.1063/1.1341218

Einstein, A., 1906, "A New Determination of Molecular Dimensions," Annalen der physik, 19(4), 289-306.

http://www.physik.uniaugsburg.de/annalen/history/einsteinpapers/1906 19289-306.pdf

El-Nasr, A.A, and El-Haggar, S.M., Effective Thermal Conductivity of Heat Pipes, 1996, Heat and Mass Transfer, Springer Verlag, 32(1), 97101.

http://link.springer.com/article/10.1007/s002310050097

Hwang, Y., Park, H.S., Lee, J.K., and Jung, W.H., 2006, "Thermal Conductivity and Lubrication Characteristics of Nanofluids," Current Applied Physics, 6(1) 67-71.

http://dx.doi.org/10.1016/j.cap.2006.01.014

Huminic, G., and Huminic, A., 2011, "Heat Transfer Characteristics of a Two-Phase Closed Thermosyphons using Nanofluids," Experimental Thermal and Fluid Science, 35(3), 550-557.

http://dx.doi.org/10.1016/j.expthermflusci.2010.12.009

Huminic, G., Huminic, A., Morjan, I., and Dumitrache, F., 2011, "Experimental Study of the Thermal Performance of Thermosyphon Heat Pipe using Iron Oxide Nanoparticles," International Journal of Heat and Mass Transfer, 54(1-3), 656-661.

http://dx.doi.org/10.1016/j.ijheatmasstransfer.2010.09.005

Hung, Y., Teng, T., and Lin, B., 2012, "Evaluation of the Thermal Performance of a Heat pipe using Alumina Nanofluids," Experimental Thermal and Fluid Science, 44, 504-511.

http://dx.doi.org/10.1016/j.expthermflusci.2012.08.012 
Kang, S., Wei, W., Tsai, S., and Huang, C., 2009, "Experimental Investigation of Nanofluids on Sintered Heat Pipe Thermal Performance," Applied Thermal Engineering, 29(5-6), 973-979. http://dx.doi.org/10.1016/j.applthermaleng.2008.05.010

Kang, S., Wei, W., Tsai, S., and Yang, S., 2006, "Experimental Investigation of Silver Nanofluid on Heat Pipe Thermal Performance," Applied Thermal Engineering, $26 \quad$ (17-18), 2377-2382. http://dx.doi.org/10.1016/j.applthermaleng.2006.02.020

Kiatsiriroat, T., Nuntaphan, A., and Tiansuwan, J., 2000, “Thermal Performance Enhancement of Thermosyphon Heat Pipe with Binary Working Fluids," Experimental Heat Transfer, 13(2), 137-152. http://dx.doi.org/10.1080/089161500269517

Kreith, F., and Bohn, M.S., 1997, Principles of heat transfer, $5^{\text {th }}$ edition, PWS publishing company, 692-710.

Li, J.M., Li, Z.L., and Wang, B.X., 2002, "Experimental Viscosity Measurement of Copper Oxide Nanoparticles Suspensions," Tsinghua Sci. Technology, 7(2), 198-201.

http://ieeexplore.ieee.org/stamp/stamp.jsp?tp=\&arnumber=6077298\&sn umber $=6077281$

Liu, M., Lin, M.C., Huang, I., and Wang, C., 2005, "Enhancement of Thermal Conductivity with Carbon Nanotube for Nanofluids," International communication in heat and mass transfer, 32(9), 12021210.

http://dx.doi.org/10.1016/j.icheatmasstransfer.2005.05.005

Liu, M., Lin, M.C., Tsai, C.Y., and Wang, C., 2006, "Enhancement of Thermal Conductivity with $\mathrm{Cu}$ for Nanofluid using Chemical Reduction Method," International Journal of Heat Mass Transfer, 49(17-18), 3028-3033.

http://dx.doi.org/10.1016/j.ijheatmasstransfer.2006.02.012

Liu, Z.H., and Zhu, Q.Z., 2011, "Application of Aqueous Nanofluids in a Horizontal Mesh Heat Pipe," Energy Conversion and Management, 52(1), 292-300.

http://dx.doi.org/10.1016/j.enconman.2010.07.001

Li, X., Zhu, D., and Wang, X., 2007, "Evaluation on Dispersion Behavior of the Aqueous Copper Nano-Suspensions," J. Colloid Interface Sci., 3(10), 456-463.

http://dx.doi.org/10.1016/j.jcis.2007.02.067

Li, Y., Zhou, J., Tung, S., Schneider, E., and Xi, S., 2009, “A Review on Development of Nanofluid Preparation and Characterization," Powder Technology, 196(2), 89-101.

http://dx.doi.org/10.1016/j.powtec.2009.07.025

Liu, Z., Li, Y., and Bao, R., 2011, "Compositive Effect of Nanoparticle Parameter on Thermal Performance of Cylindrical Microgrooved Heat Pipe using Nanofluids," International Journal of Thermal Sciences, 50(4), 558-568.

http://dx.doi.org/10.1016/j.ijthermalsci.2010.11.013

Liu, Z., Li, Y., and Bao, R., 2010, "Thermal Performance of Inclined Grooved Heat Pipes using Nanofluids," International Journal of Thermal Sciences, 49(9), $1680-1687$.

http://dx.doi.org/10.1016/j.ijthermalsci.2010.03.006

Moraveji, M.K., and Razvarz, S., 2012, "Experimental Investigation of Aluminum Oxide Nanofluid on Heat Pipe Thermal Performance," International Communication in Heat and Mass Transfer, 39(9), 14441448 .

http://dx.doi.org/10.1016/j.icheatmasstransfer.2012.07.024
Mousa, M.G., 2011, "Effect of Nanofluid Concentration on the Performance of Circular Heat Pipe," International Journal of Scientific \& Engineering Research, 2(4), 2229-5518.

Murshed, S.M.S., 2012, "Simultaneous Measurement of Thermal Conductivity, Thermal Diffusivity, and Specific Heat of Nanofluids," Heat Transfer Engineering, 33(8), 722-731.

http://dx.doi.org/10.1080/01457632.2011.635986

Murshed, S.M.S., Leong, K.C., and Yang, C., 2005, "Enhanced Thermal Conductivity of $\mathrm{TiO}_{2}$ Water Based Nanofluid," International Journal of Thermal Sciences, 44(4), 367-373.

http://dx.doi.org/10.1016/j.ijthermalsci.2004.12.005

Naphon, P., Assadamongkol, P., and Borirak, T., 2008, "Experimental Investigation of Titanium Nanofluids on the Heat Pipe Thermal Efficiency," International Communications, in Heat and Mass Transfer, 35(10), 1316-1319.

http://dx.doi.org/10.1016/j.icheatmasstransfer.2008.07.010

Naphon, P., Thongkum, D., and Assadamongkol, P., 2009, "Heat Pipe Efficiency Enhancement with Refrigerant Nanoparticles Mixtures," Energy Conversion and Management, 50(3), 772-776.

http://dx.doi.org/10.1016/j.enconman.2008.09.045

Noie, S.H., Heris, S.Z, Kahani, M., and Nowee, S.M., 2009, "Heat Transfer Enhancement using $\mathrm{Al}_{2} \mathrm{O}_{3}$-water Nanofluid in a Two-Phase Closed Thermosyphon," International Journal of Heat and Fluid Flow, 30(4), 700-705.

http://dx.doi.org/10.1016/j.ijheatfluidflow.2009.03.001

Peng, X., Yu, X., 2007, "Influence Factors on Suspension Stability of Nanofluids,” J. Zhejiang Univ.: Engineering. Science, 41, 577-580.

Senthilkumar, R., Vaidyanathan, S., and Sivaraman B., 2011, "Experimental Analysis of Cylindrical Heat Pipe Using Copper Nanofluid with an Aqueous Solution of n-Hexanol," Frontier in Heat Pipes, 2,033004.

http://dx.doi.org/10.5098/fhp.v2.3.3004

Senthilkumar, R., Vaidyanathan, S., and Sivaraman B., 2010, "Performance Analysis of Heat Pipe Using Copper Nanofluid with Aqueous Solution of n-Butanol," International Journal of Mechanical and Materials Engineering, 1(4), 251-256.

https://www.waset.org/journals/ijmme/v1/v1-4-38.pdf

Shafahi, M., Bianco, V., Vafai, K., and Manca, O., 2010, "An Investigation of the Thermal Performance of Cylindrical Heat Pipes using Nanofluids," International Journal of Heat and Mass Transfer, 53(1-3), 376-383.

http://dx.doi.org/10.1016/j.ijheatmasstransfer.2009.09.019

Sharma, P., Baek, I., Cho, T., Park, S., and Lee, K.B., 2011, "Enhancement of Thermal Conductivity of Ethylene Glycol Based Silver Nanofluids," Powder Technology, 208(1), 7-19.

http://dx.doi.org/10.1016/j.powtec.2010.11.016

Singh, N., Chand, G., and Kanagaraj, S., 2012, "Investigation of Thermal Conductivity and Viscosity of Carbon Nanotubes-Ethylene Glycol Nanofluids," Heat Transfer Engineering, 33(9), 821-827. http://dx.doi.org/10.1080/01457632.2012.646922

Teng, T., Hsu, H., Mo, H., and Chen, C., 2010, "Thermal Efficiency of Heat Pipe with Alumina Nanofluid," Journal of Alloys and Compounds, 504(1), S380-S384.

http://dx.doi.org/10.1016/i.jallcom.2010.02.046 
Tsai, C.Y., Chien, H.T., Ding, P.P., Chan, B., Luh, T.Y., and Chen, P.H., 2004, "Effect of Structural Character of Gold Nanoparticles in Nanofluid on Heat Pipe Thermal Performance," Materials Letters, 58(9), 1461- 1465 .

http://dx.doi.org/10.1016/j.matlet.2003.10.009

Venerus, D.C., Buongiorno, J., Christianson, R., Townsend, J., Bang, I.C., Chen, G., Chung, S.J., Chyu, M., Chen, H., Ding, Y., Dubois, F., Dzido, G., Funfschilling, D., Galand, Q., Gao, J., Hong, H., Horton, M., Hu, L., Iorio, C.S., Jarzebski, A.B., Jiang, Y., Kabelac, S., Kedzierski, M.A., Kim, C., Kim, J., Kim, S., McKrell, T., Ni., R., Philip., J., Prabhat, N., Song, P., Vaerenbergh, S.V., Wen, D., Witharana, S., Zhao, X., Zhou, S., 2010, "Viscosity Measurements on Colloidal Dispersions (Nanofluids) for Heat Transfer Applications," Applied Rheology, Vol. 20, 44582.

DOI: $10.3933 / \mathrm{ApplRheol-20-44582}$

Wang, G., Song, B., and Liu, Z., 2010, "Operation Characteristics of Cylindrical Miniature Grooved Heat Pipe using Aqueous $\mathrm{CuO}$ Nanofluids," Experimental Thermal and Fluid Science, 34(8), 14151421.

http://dx.doi.org/10.1016/j.expthermflusci.2010.07.004
Wei, W., Tsai, S., Yang, S., and Kang, S., 2005, "Effect of Nanofluid on Heat Pipe Thermal Performance," Proc. 3rd IASME/WSEAS Int. Conf. on Heat Transfer, Thermal Engineering and Environment, Corfu, Greece, 115-117.

Xie, H., Wang, J., Xi, T., Liu, Y., Ai, F., and Wu, Q., 2002, “Thermal Conductivity Enhancement of Suspensions Containing Nano sized Alumina Particle," Journal of Applied Physics, 9(7), 4568 - 4572. http://dx.doi.org/10.1063/1.1454184

Xuan, Y., and Li, Q., 2000, "Heat Transfer Enhancement of Nanofluids," International journal of Heat Mass Transfer, 21(1), 5864.

http://dx.doi.org/10.1016/S0142-727X(99)00067-3

Zhang, X., Gu, H., and Fujii, M., 2007, "Effective Thermal Conductivity and Thermal Diffusivity of Nanofluids Containing Spherical and Cylindrical Nanoparticles," Experimental Thermal and Fluid Science, 31(6), 593-599.

http://dx.doi.org/10.1016/j.expthermflusci.2006.06.009 